\title{
Crystallization of the Racemic Conglomerate and Racemic Compound of Efonidipine
}

\author{
Linyuan $\mathrm{ZHU}^{1, \mathrm{a}}$ \\ ${ }^{1}$ Zhengzhou Foreign Language School New Fengyang \\ Campus \\ Zhengzhou 450001, China \\ a e-mail:2891541380@qq.com
}

\author{
Zhanjun $\mathrm{LI}^{2, \mathrm{~b}}$, Yuzhen $\mathrm{YU}^{2, \mathrm{c}}$ \\ ${ }^{2}$ School of Chemical Engineering and Energy \\ Zhengzhou University \\ Zhengzhou 450001, China \\ b e-mail:3441073919@qq.com, \\ c e-mail: 924094112@qq.com
}

\section{Wen $\mathrm{LI}^{3, \mathrm{~d}, \text {, }}$ \\ ${ }^{3}$ School of Pharmaceutical Sciences \\ Zhengzhou University \\ Zhengzhou 450001, China \\ d584508809@qq.com}

is simpler, greener and more cost-effective than any other methods ${ }^{[2]}$.

\begin{abstract}
Efonidipine is a dual blocker of T-type and L-type calcium channels with 1, 4-dihydropyridine structure attached to a phosphonate skeleton. As a chiral compound, it has a special property that can exist as a racemic conglomerate or a racemic compound based on the different crystallization conditions. One racemic conglomerate and one racemic compound were disclosed and characterized in this research. Efonidipine conglomerate could obtain from its racemic solution when ethanol, methanol, tetrahydrofuran, ethyl acetate and acetonitrile were chosen as the crystallized solvent. While, racemic compound which existed as an acetone solvate could be prepared by crystallization from acetone only and the crystallization process must be keep stood without agitating. In order to confirm this conclusion, three single crystals of R-efonidipine, S-efonidipine and R/S- efonidipine acetone solvate have been prepared and determined.
\end{abstract}

Keywords-efonidipine; crystallization; racemic conglomerate; racemic compound

\section{INTRODUCTION}

There are three different kinds of racemates: the racemic conglomerate or named conglomerate, racemic compound or called true racemate, and racemic solid solution (pseudoracemate) $^{[1]}$.

The racemic conglomerate consists of a physical mixture of pure crystals of the two isomers. There are only $5 \%$ to $10 \%$ probabilities of all organic compounds to form conglomerate when they crystallized from a racemic solution. Conglomerate-forming crystals molecular have a stronger affinity for the same isomers than for the two isomers or the counterpart crystallize separately. The formation of conglomerate provides a means to obtain pure enantiomers of organic compounds by direct crystallization separation which
The racemic compound is formed by a single crystal in which the two isomers pack against each other in a regular fashion with a 1:1 ratio. There are about $90 \%$ probabilities of all organic compounds to form racemic compound. In this crystals, molecular have a stronger affinity for the counterpart than for the same isomers ${ }^{[2]}$.

In the pseudoracemate crystal, the isomers are in equal proportions but are packed in random fashion. There are rare probabilities of all organic compounds to form pseudoracemate crystals. In this crystals, molecular have no significant difference of the affinity for the same isomers or the counterparts ${ }^{[2]}$.

Each racemic mode has its own physical characteristics, such as the structure, melting temperature, solubility, and density ${ }^{[3]}$.

Efonidipine, ( \pm )-2-[benzyl (phenyl) amino] ethyl 1,4-dihydro-2,6-dimethyl-5- (5,5-dimethyl - 2-oxo -1, 3, 2-dioxaphosphorinan-2-yl)-4-(3-nitrophenyl)-3-pyridine-car boxylate (Fig. 1a), is a dual blocker of T-type and L-type calcium channels with 1,4-dihydropyridine structure attached to a phosphonate skeleton. Its hydrochloride monoethanolate is already being marketed in Japan by Shionogi \& Co., Ltd. and ZERIA pharmaceutical Co., Ltd as an antihypertensive and antianginal drug. The drug exhibits a longer half-life, better hydrophilicity and bioavailability than existing $\mathrm{Ca} 2+$ antagonists and appears to have an ideal profile with organ-protective effects in heart and kidney.

Efonidipine exists as a racemate consists of R-enantiomer (Fig. 1b) and S-enantiomer (Fig. 1c) due to a chiral center in 1, 4-dihydropyridine. R-enantiomer and S-enantiomer exhibits completely different biological activities ${ }^{[4,5]}$ and have been used in different fields which is the case for most chiral drugs. 


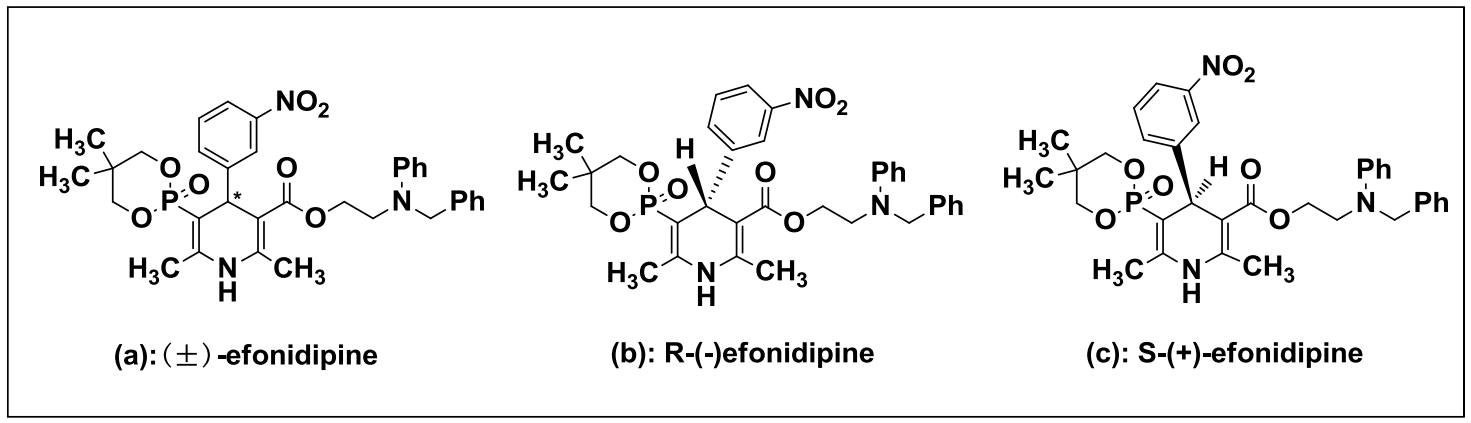

Figure 1. Chemical structure of Efonidipine

Asymmetric synthesis of $\mathrm{S}$ - efonidipine isomer and its crystal structure has been reported by R. Sakoda [6] in 1992. Recently, M. Otsuka group reported the stability and physicochemical characterization of efonidipine hydrochloride ethanolate [7]. But, the formation and characterization of the racemates of efonidipine has not been reported. Regarding the advantages of direct crystallization, the screen of all possible types of efonidipine racemates has a crucial significance. One racemic conglomerate and one racemic compound in the form of an acetone solvate were disclosed and characterized in this research. Efonidipine conglomerate could obtain from multiple crystallized solvent very easily. While, racemic compound which existed as an acetone solvate could be prepared by crystallization from acetone only and the crystallization process must be keep stood without agitating (Fig. 2).

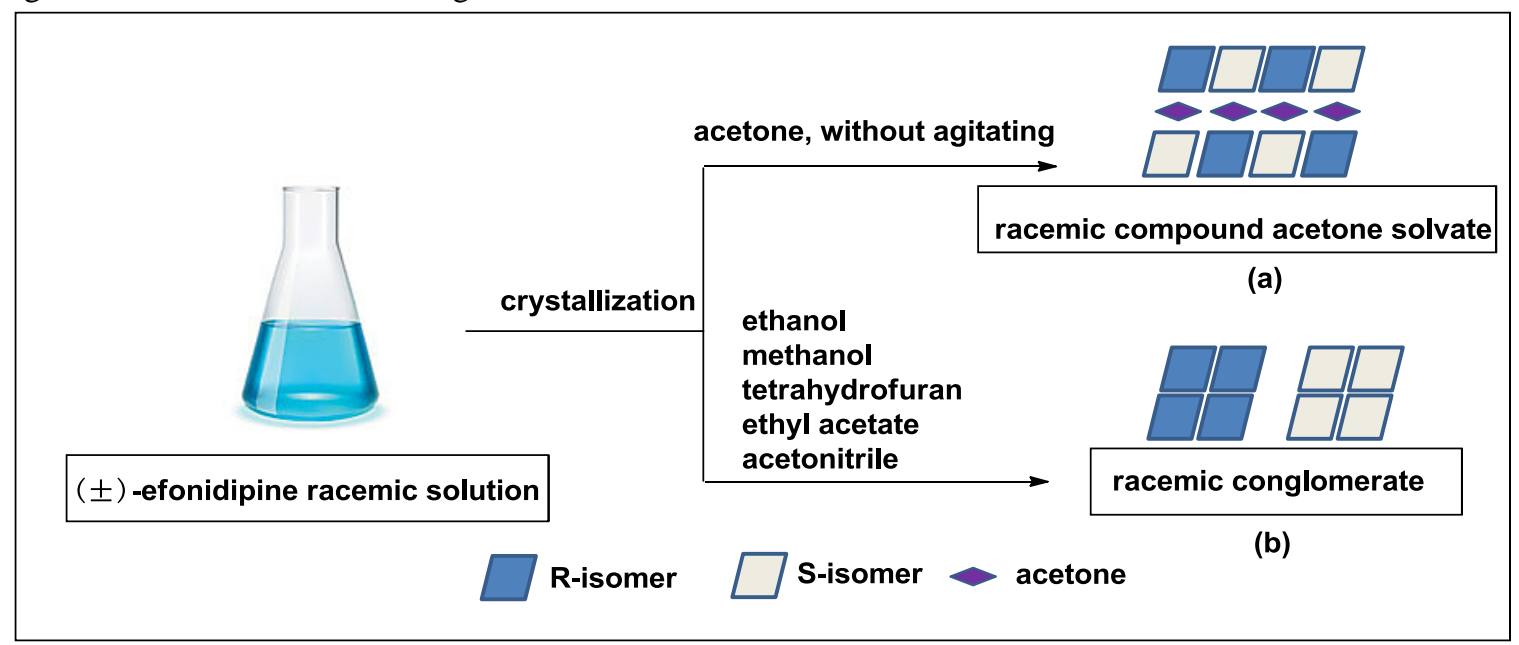

Figure 2. Different types of Efonidipine racemates

\section{EXPERIMENTAL}

\section{A. Materials:}

Efonidipine were supplied by Furen Pharmaceutical Technology Development Co., Ltd as a racemate. All other chemicals and reagents used were analytical reagent grade.

\section{B. Single Crystal Formation and X-Ray Diffraction Data Collection:}

Three single crystals of R-efonidipine, S-efonidipine and $\mathrm{R} / \mathrm{S}$ - efonidipine acetone solvate have been prepared and determined in this study.

To prepare single crystal of $\mathrm{R} / \mathrm{S}$ - efonidipine acetone solvate, efonidipine racemic powder was added to acetone, at approximately $55-65^{\circ} \mathrm{C}$ to fully dissolve. The resulting solution was then left undisturbed at room temperature for three days and the crystallization process was keep stood 
without agitating. The yellow-green prismatic shape crystals were collected by filtration.

To prepare R-efonidipine and S-efonidipine single crystal which existed as a racemic conglomerate, efonidipine racemic powder was added to ethanol, at approximately $70-75^{\circ} \mathrm{C}$ to fully dissolve the compound. The resulting solution was then left undisturbed at room temperature for three days. The yellow prismatic shape crystals of $\mathrm{R}$-efonidipine isomer and $\mathrm{S}$ - efonidipine isomer single crystals obtained by stochastically.

R-efonidipine and S-efonidipine single crystal which existed as a racemic conglomerate could be also formed when methanol, tetrahydrofuran, ethyl acetate and acetonitrile were chose as the crystallization solvents.

Single crystal X-ray diffraction data were collected at 291 $\mathrm{K}$ on a Rigaku Gemini $\mathrm{E}$ with monochromated $\mathrm{CuK} \alpha$ radiation $(\lambda=1.54184 \AA)$. The structures were solved by direct methods using ShelXS structure solution program and refined by the ShelXL refinement package.

\section{RESULTS AND DISCUSSION}

\section{The Single Crystal of Efonidipine Isomers}

$\mathrm{R} / \mathrm{S}$ - efonidipine acetone solvate, R-efonidipine and S-efonidipine single crystals (Fig. 3) were obtained from a racemate solution when the conditions of recrystallization were studied. The crystallographic parameters of our crystals are summarized in Table 1.

$\mathrm{R} / \mathrm{S}$ - efonidipine acetone solvate single crystal was a novel structure which has not been reported by anyone. Its crystal structure belongs to triclinic, space group P-1.

$\mathrm{R}$-efonidipine and S-efonidipine single crystals were selected at the same crystal conditions through random screening and the crystallographic parameters were in accordance with previously reported values. Their crystal structures belong to monoclinic, space group P212121.

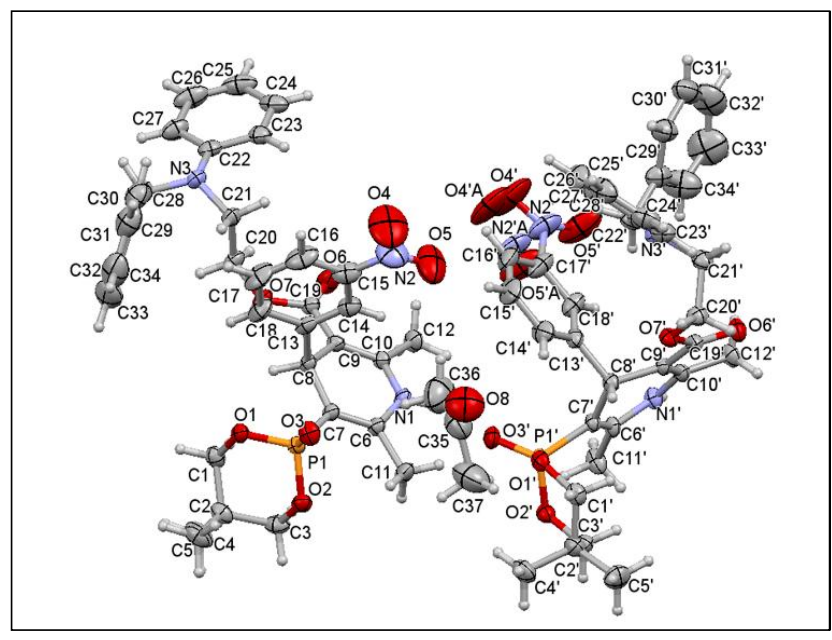

R/S- efonidipine acetone solvate (a)

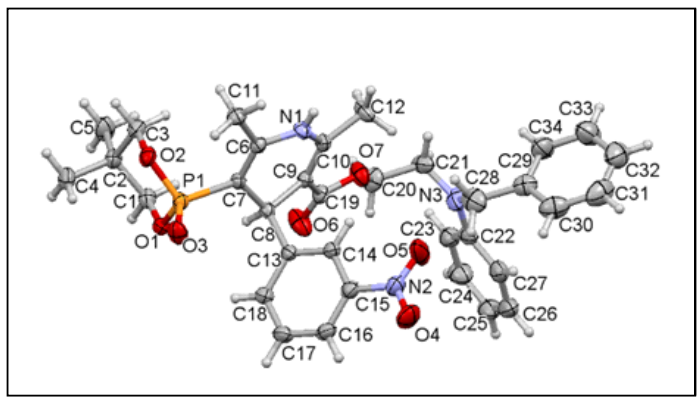

R-efonidipine (b)

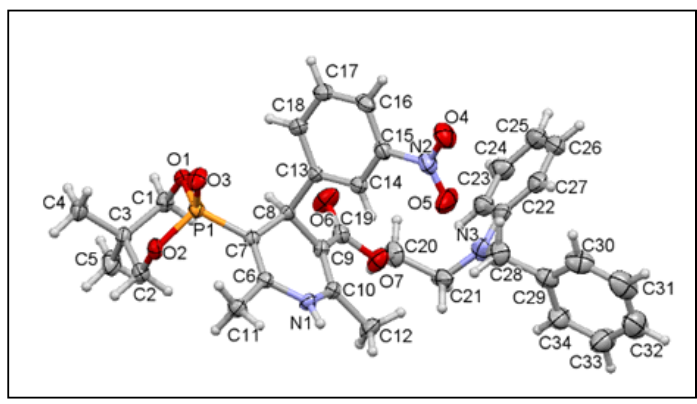

S-efonidipine (c)

Figure 3. Crystal structure of the R/S- efonidipine acetone solvate (a), R-efonidipine (b) and S-efonidipine (c) 
TABLE I. CRYSTALLOGRAPHIC PARAMETERS OF R/S- EFONIDIPINE ACETONE SOLVATE, R-EFONIDIPINE AND S-EFONIDIPINE

\begin{tabular}{|c|c|c|c|}
\hline & $\begin{array}{l}\mathrm{R} / \mathrm{S} \text { - efonidipine } \\
\text { acetone solvate }\end{array}$ & R-efonidipine & S-efonidipine \\
\hline Molecular formula & $\left(\mathrm{C}_{34} \mathrm{H}_{38} \mathrm{~N}_{3} \mathrm{O}_{7} \mathrm{P}\right)_{2} \cdot \mathrm{C}_{3} \mathrm{H}_{6} \mathrm{O}$ & $\mathrm{C}_{34} \mathrm{H}_{38} \mathrm{~N}_{3} \mathrm{O}_{7} \mathrm{P}$ & $\mathrm{C}_{34} \mathrm{H}_{38} \mathrm{~N}_{3} \mathrm{O}_{7} \mathrm{P}$ \\
\hline Molecular weight & 1321.39 & 631.64 & 631.64 \\
\hline Temperature $(\mathrm{K})$ & 293 & 291 & 293 \\
\hline Crystal color, habit & Yellow-green, Prism & Yellow, Prism & Yellow, Prism \\
\hline Crystal system & triclinic & Orthorhombic & Orthorhombic \\
\hline Space group & $\mathrm{P}-1$ & $\mathrm{P} 2{ }_{1} 2_{1} 2_{1}$ & $\mathrm{P} 2{ }_{1} 2_{1} 2_{1}$ \\
\hline \multicolumn{4}{|l|}{$\begin{array}{l}\text { Lattice parameters } \\
\qquad\left(\AA,{ }^{\circ}\right)\end{array}$} \\
\hline$a=$ & $13.9972(6)$ & $9.9571(3)$ & $9.9690(3)$ \\
\hline $\mathrm{b}=$ & $17.2985(4)$ & $13.1879(3)$ & $13.1954(3)$ \\
\hline $\mathrm{c}=$ & $18.4787(6)$ & $24.6117(7)$ & $24.5856(6)$ \\
\hline$\alpha=$ & $63.723(3)$ & 90.00 & 90.00 \\
\hline$\beta=$ & $68.593(3)$ & 90.00 & 90.00 \\
\hline$\gamma=$ & $67.115(4)$ & 90.00 & 90.00 \\
\hline Volume $\left(\AA^{3}\right)$ & $3594.1(3)$ & $3231.84(15)$ & $3234.11(15)$ \\
\hline $\mathrm{Z}$ & 2 & 4 & 4 \\
\hline $\mathrm{D}_{\text {calcd }}\left(\mathrm{Mg} \mathrm{m}^{-3}\right)$ & 1.221 & 1.298 & 1.297 \\
\hline Reflections collected & 56083 & 12090 & 8060 \\
\hline $\begin{array}{l}\text { Independent } \\
\text { reflections }\end{array}$ & 12829 & 6233 & 4960 \\
\hline $\mathrm{R}_{\mathrm{int}}$ & 0.0498 & 0.0309 & 0.0263 \\
\hline $\begin{array}{c}\text { Absolute structure } \\
\text { parameter }\end{array}$ & - & $-0.059(17)$ & $0.04(2)$ \\
\hline Goodness-of-fit on $\mathrm{F}^{2}$ & 1.053 & 1.046 & 1.040 \\
\hline Final $\mathrm{R}$ indices $[I>$ & $\mathrm{R}_{1}=0.0592$ & $\mathrm{R}_{1}=0.0447$ & $\mathrm{R}_{1}=0.0447$ \\
\hline $2 \sigma(I)]$ & $\mathrm{W} \mathrm{R}=0.1774$ & $\mathrm{~W} \mathrm{R}=0.1164$ & $\mathrm{~W} \mathrm{R}_{2}=0.1052$ \\
\hline $\mathrm{R}$ indices (all data) & $\mathrm{R}_{1}=0.0657$ & $\mathrm{R}_{1}=0.0490$ & $\mathrm{R}_{1}=0.0547$ \\
\hline & $\mathrm{W} \mathrm{R}_{2}=0.1854$ & $\mathrm{~W} \mathrm{R}_{2}=0.1211$ & $\mathrm{~W} \mathrm{R}_{2}=0.1144$ \\
\hline
\end{tabular}

The analyses on crystal structures have verified that Efonidipine conglomerate could obtain from its racemic solution when ethanol was chosen as the crystallized solvent. The same results were got when ethanol solvent was substituted by another solvent such as methanol, tetrahydrofuran, ethyl acetate and acetonitrile. While,

\section{CONCLUSION}

The types of Efonidipine racemates were explored by single crystals XRD in this research. The conditions of how to obtain racemic conglomerate and racemic compound of Efonidipine have been revealed. Unlike most organic compounds, this work finds that the preparation of Efonidipine conglomerate is very simple and convenient while the preparation of Efonidipine racemic compound is very difficult. It might be explained that the molecular affinity between the same isomers of Efonidipine are stronger than that between the different isomers. The favorable stability and the convenient preparation process of efonidipine conglomerate enhance the possibility of direct crystallization utilization. racemic compound which existed as an acetone solvate could be prepared by crystallization from acetone only and the crystallization process must be keep stood without agitating. The racemic compound unsolvate has not been obtained in this study.

\section{ACKNOWLEDGEMENT}

The authors are grateful to the Analysis and Testing Center of Zhengzhou University for the single-crystal X-ray diffraction other data collection. This work was supported by Science and Technology Bureau of Henan through the Cooperation Research (Project funds no. 152107000043 for W. L.), the Education Bureau of Henan for Major Research (Project funds no. 14A530007 for W. L.). We also thank Dr. Xiaolan Yao of University of Missouri-Kansas City for the critical reading of this manuscript.

\section{REFERENCES}

[1] J. Jacques, A. Collet, S.H. Wilen. Enantiomers, Racemates, and Resolutions. Malabar, Fla, 1991.

[2] [R.J.Davey, G.Sadiq, C.C. Seaton, Racemic compound versus conglomerate: Concerning the crystal chemistry of the triazoylketone, 
1-(4-chlorophenyl)-4,4-dimethyl-2-(1H-1,2,4- triazol $\quad-1-y l)$ pentan-3-one, CrystEngComm. 16 (2014) 4377-4381.

[3] R. F. Robert, L. Heike, A. Zemfira, A. et al, Solubility and some crystallization properties of conglomerate forming chiral drug guaifenesin in water, J Pharm Sci. 103 (2014) 3176-3182.

[4] Hu, T. Mori, Y. Lu, et al, Role of specific T-type calcium channel blocker $\mathrm{R}$ (-)-efonidipine in the regulation of renal medullary circulation, J Hypertens. 30 (2012) 1620-1631.

[5] N. Hashimoto, T. Kawazu. Pharmacological Profiles of T-Type Calcium Channel Antagonists, Springer Vienna, New York, 2015, pp.37-48.
[6] R. Sakoda, H. Matsumoto, K. Seto, Synthesis and Crystal Structure of Optically Active 2-(Benzyl(phenyl) amino)ethyl 5-(5,5-Dimethyl-2-oxo-1,3,2-dioxaphosphorinan-2-yl)- 1, 4- dihydro 2, 6 - dimethyl 1- 4 -(3-nitrophenyl)-3-pyridinecarboxylate (NZ-105), Chem Pharm Bull. 40 (1992) 2377-2381.

[7] M.Otsuka, Y.Maeno, T.Fukami, et al, Developmental considerations for ethanolates with regard to stability and physicochemical characterization of efonidipine hydrochloride ethanolate, CrystEngComm. 17 (2015) 7430-7436. 